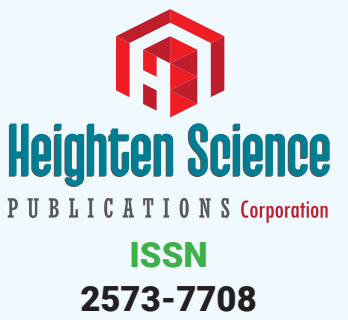

*Address for Correspondence: Dr. Syed Abdul Kader, MBBS, MD, Assistant Professor, Department of Endocrinology and Metabolism, Sher-e-Bangla Medical College, Barisal, Bangladesh, Email: skdr0002@gmail.com

Submitted: 13 May 2019

Approved: 03 June 2019

Published: 04 June 2019

Copyright: @ 2019 Kader SA. This is an open access article distributed under the Creative Commons Attribution License, which permits unrestricted use, distribution, and reproduction in any medium, provided the original work is properly cited

Keywords: Feet; Hyponatraemia; Bulla; Hoffman's sign

Check for updates
Review Article

\section{A few observations of clinical importance}

\author{
Syed Abdul Kader* \\ Assistant Professor, Department of Endocrinology and Metabolism, Sher-e-Bangla Medical \\ College, Barisal, Bangladesh
}

\section{Abstract}

This article reflects the opinion on a few of my clinical experiences involving symptoms and signs which are not mentioned in standard textbooks on medicine or clinical methods. These are clinical and a few radiological signs which I think worth discussing by clinical community, includes Muslim prayer's feet, hyponatraemic bullae, early signs of oedema, PCV sign, hemi-semiHoffman's sign and a few more.

\section{Introduction}

Knowledge and best practice in medicine is constantly changing. As new research and experience broaden our understandings, changes in research methods, professional practices, or medical treatment may become necessary. Practitioners and researchers must rely on their own experience and knowledge in evaluating and using any information, methods, compounds or experiments [1]. There are two steps clinical diagnosis, establishment of clinical database and its interpretation [2]. Knowledge, common sense and sound reasoning is necessary for the correct clinical diagnosis, and our predecessors, the pioneers of medicine depended more on the latter two, for they created knowledge.

\section{Muslim prayer's feet}

In devout Muslims of working class religious habit of praying in 'Salah' [3] all the five times or 'Waqts' [3] all the 'Rakats' $[3,4]$, including obligatory ones together with occupation shapes their feet. Feet of many of them are medially deviated in an attempt to direct toes towards 'Qiblah' [3,4]. Most of them have corns and callosities on the dorsum of their left feet and foreheads.

Extent, pattern and duration of stress on the feet matter. I didn't think it would be appropriate to take a photo of those feet in the premises of the mosque at that time but I captured two pictures of a similar pair of feet in the hospital.

Though he was a younger person (Figure 1a) in his late thirties actually admitted with fever. We know about corns and callosities, but I have not heard of or read about this medial deviation of feet. I call it 'Muslim Prayer's feet'. The older person (Figure 1b) presented with stroke with cerebral acute infarction and haemrrahage at two different sites which seemed to be simultaneous (Figure 2).

\section{Hyponatraemic bullae}

Figure 3 shows a clinical picture which I find often in the ward without any specific mention of this clinical association in the textbooks. I saw, many a times, chemosis, 
conjunctival and sometimes lower eyelid bullae in patients developing moderate to severe hyponatraemia, usually hypervovolaemic hyponatraemia, sometimes with hyponatraemia with myxoedema coma. The patients in the picture did not have much of facial oedema, but had bullous lower eyelids. He had, at that time, a serum sodium level of $105.46 \mathrm{meq} / \mathrm{L}$. These bullae are very superficial. Probably, low concentration of hypontraemic serum provides a greater chance of fluid coming out of vessels to that superficial a space. I would like to call these lesions hypontraemic bullae. Figure 4 shows chemosis and conjunctival bulla in a different patient.

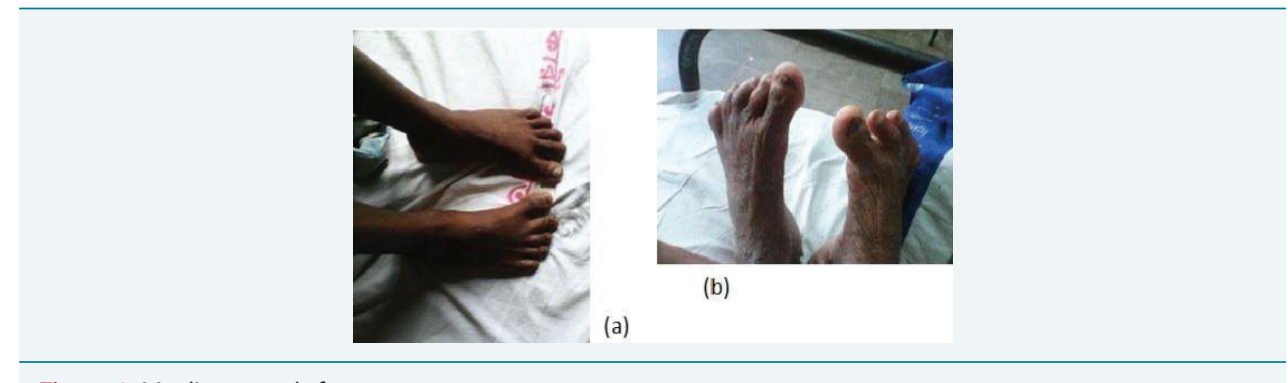

Figure 1: Muslim prayer's feet.



Figure 2: Two different sites which seemed to be simultaneous.

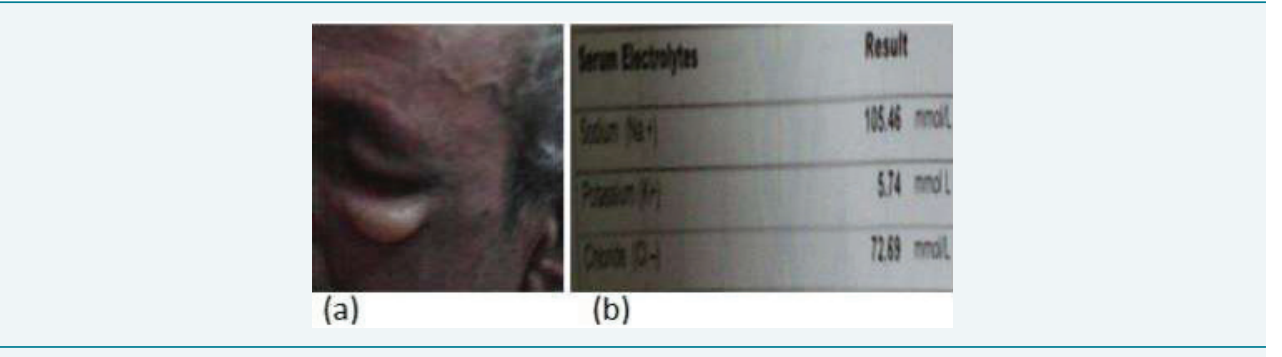

Figure 3: Clinical picture.



Figure 4: Shows chemosis and conjunctival bulla in a different patient. 


\section{Hemi-semi-hoffman sign}

The patient in figure 5 presented with neck-pain and weakness in the left hand. She had wasted thenar eminence. On X-ray cervical spine she had narrow intervertebral spaces especially between C5 and C6, and probably soft tissue reaction at the same level on the left side. Remarkably, Hoffman's response [5], could be elicited in her ulnar two fingers of the left hand, and in contrast, lower motor signs in the other fingers and radial part of the left hand. We can call it Hemi-semi-Hoffman sign.

\section{PCV sign}

Subdural haematoma when presented within 72 hours of occurrence is called acute subdural haematoma, when between 4 and 21 days subacute subdural haematoma, when after 21 days chronic subdural haematoma. In acute subdural haematoma unabsorbed blood crescentic hyperdensity on CT scan of brain, hypodensity of the same shape in chronic subdural haematoma. In subacute subdural haematoma density is in between hyper and hypodensity or isodense, but more often than not the blood cells settle down and separate from fluid portion in the same way it separates in ESR (Erythrocyte Sedimentation Rate) estimation to a much lesser extent in one hour or in PCV (Packed Cell Volume) estimation to a much similar extent in much quicker time with the help of rapid centrifugation. We can call it PCV sign (Figures 6-8).

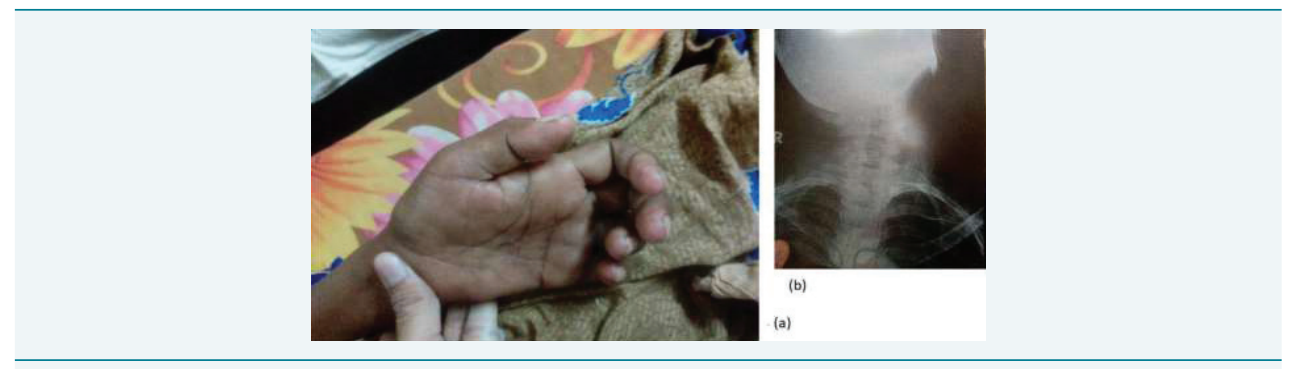

Figure 5: Neck-pain and weakness in the left hand.

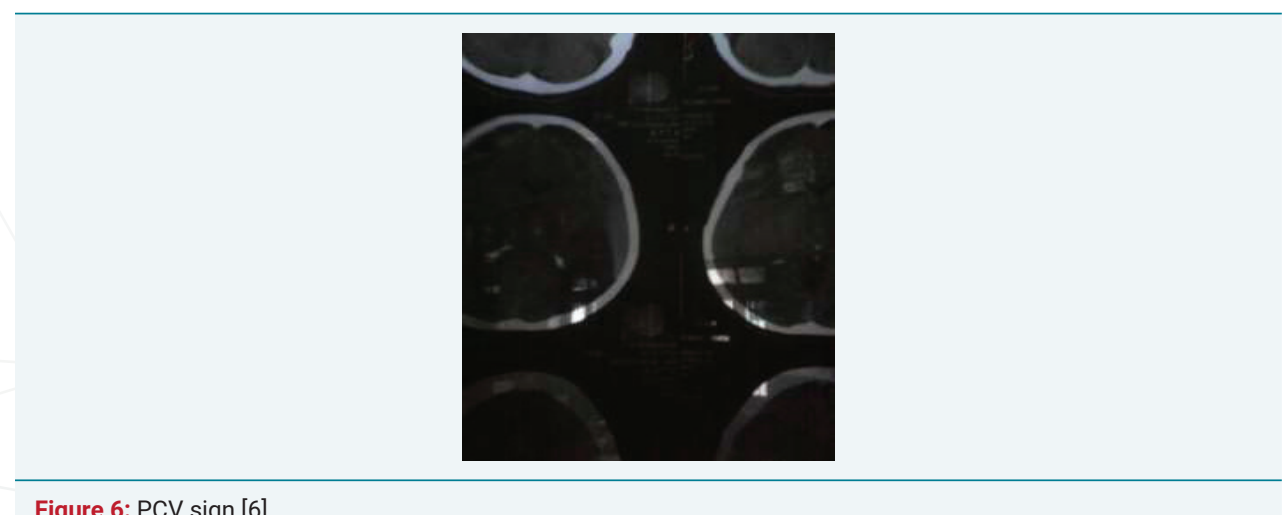

Figure 6: PCV sign [6]



Figure 7: PCV sign. From emedicine.medscape.com [7]. 




\section{Early signs of oedema}

We all know where to see oedema, and in which condition where oedema develops first and preferentially. We can also notice the early signs of odema (Figure 9), gradual disappearance of skin creases over joints, gradual non-visualisation of veins in the limbs which are dependent, subcutaneous engorgement causing skin shininess, microvascular compromise and fall of hair, there might be leukonychia to indicate the cause.

\section{Ups and downs with Down's}

In the mid-August 2015 a young gentleman with Down syndrome got admitted to medicine ward of SBMCH with urinary retention and sonographic evidence of bilateral hydronephrosis. Retention was relieved by catheterization, and he was sent to one of the urology beds of surgery ward. He looked quite jovial throughout the proceeding with smile on his face, with his hand gently placed on mine, with his small hand showing clear signs of clinodactyly of little finger and simian crease (Figure 10). How much he felt the agony of retention? We know that Down syndrome may be associated with non-neurogenic neurogenic bladder. Could it be it? Could it be complicated by



Figure 9: Early signs of oedema.

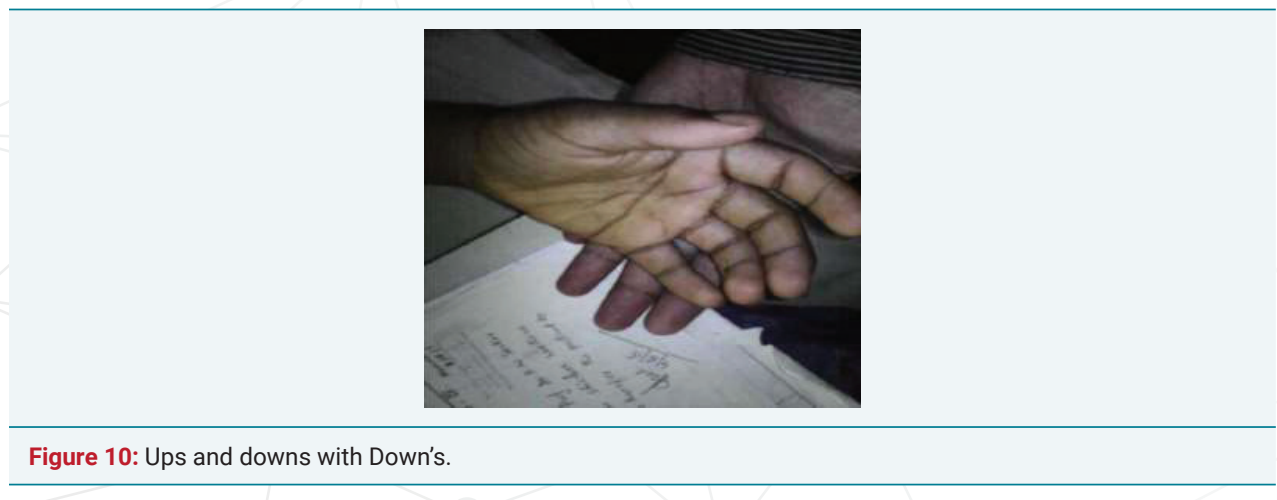


hydronephrosis? Associations with hypothyroidism and diabetes mellitus are quite common in these patients, so are congenital heart diseases and different types of leukaemia. We should watch out for these conditions to give somewhat longer and more comfortable life of these patients.

\section{Metabolic side of ichthyosis}

Ichthyosis patients present with dry, thick, fish like scaly skin, the commonest congenital form being autosomal dominant ichthyosis vulgaris. The patients with this disease cannot sweat well. However rare it may be, it doesn't seem so rare among beggars in the streets of Dhaka. I interviewed one of them whose brother had the same condition (Figure 11). Severest form of the congenital disease, along with loss of temperature regulation and water loss, has severe vitamin-D deficiency. I saw a few of the ichthyosis patients with bent legs. I saw one of such patients repeatedly pouring water on his body to keep the skin moist. Weather temperature approximating body temperature means less heat loss. The greater humidity of weather leads to less evaporation from the body, and skin taking up the humidity from the atmosphere becoming less dry. So, ironically, hot and humid weather suits ichtyosis patients' comfort.

\section{Mass hysteria}

What we know about mass hysteria, mass psychogenic illness or mass epidemic illness is that it manifests as a collection of symptoms, typically, nausea, muscle weakness, fits or headache which begins in one individual and spread to others, usually of the same group of people, who has seen the symptoms of index or subsequent cases. In the last week of August 2015, this happened in Barisal. A lot of school students rushed to hospitals with mass hysteria ringing an alarm bell in the population and medical personnel in the area. Rush of patients was so much they had to find their place in the space between the wards in SBMCH. Incidence of mass hysteria has been noticeable in Bangladesh in increasing frequency and intensity in the recent years. This time, probably, junior school certificate examination worked as a trigger factor. Community psychiatrist could be employed particularly in the schools and other vulnerable institutions to prevent this problem (Figure 12).

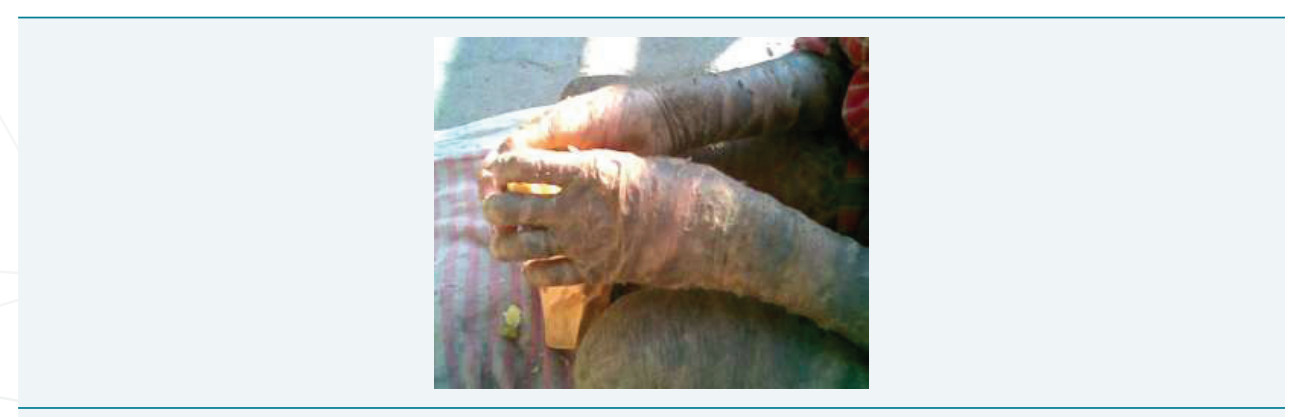

Figure 11: Metabolic side of ichthyosis

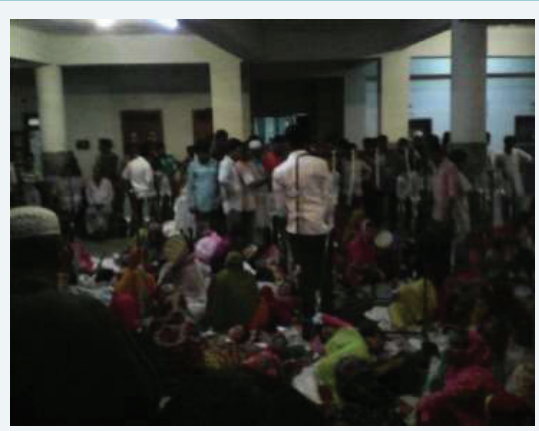

Figure 12: Mass hysteria. 
Broadened and lengthened intercostal space in massive pleural effusion and reduction by thoracentesis

Intercostal spaces could be broadened and lengthened in massive pleural effusion (Figure 13) which could observed in chest X-ray and on palpation clinically. Thoracentesis brings about reduction of expansion of these spaces as well as deviation of mediastinum to opposite side and reduction of elevation of the first rib (Figure 14(a) before and (b) after thoracentesis).

\section{Fallacies of clinical signs}

It is interesting how life, livelihood, surrounding and the other conditions of the body affect interpretation of clinical signs. Sub-continental people use bare hand to take food which is spicy, rich in turmeric and dried chili powder. Housewives and cooks make paste out of turmeric with their bare hands and basic tools of stone. Believe only sclera while assessing jaundice of these people. Yellow light, yellow window pane, wall painted deep yellow reflecting light with patient in the line of reflected rays may make the interpretation of jaundice difficult. Fallen teeth on one side make an easier outlet of protruding tongue mimicking hypoglossal nerve palsy on that side. Overlapping teeth on one side may cause asymmetric labial apposition resembling facial palsy on that side. Unilateral painful stimuli may produce movement and grimacing on that side only in an unconscious patient mimicking hemiparesis. It is wise to be systematic here with correlation of components of details of observation. On a round in 2015, I saw a dyspnoeic patient with more than thirty pack-years of smoking history behind him. His chest X-ray showed two big partially emptied abscess cavities in the lower zone of the right lung field. Interestingly, he didn't cough out as much sputum as expected of a typical lung abscess patient. There were no amphoric or bronchial breath sound, no increase in vocal fremitus and resonance over the lesions. It seemed something is hindering the patency of bronchus proximal to the abscesses with their aeration and drainage being impaired. A directed and informed look could delineate a bulge



Figure 13: Broadened and lengthened intercostal space in massive pleural effusion and reduction by thoracentesis



(a)



(b)

Figure 14: (a) before and (b) after thoracentesis. 
from the right hilum. So, it could be bronchogenic carcinoma in the setting of clinical scenario. Multiple abscesses in the same region of the same lung add to the set of information that gives clue to the diagnosis. Here is the importance of 'check, think, recheck' approach. This case could give rise to clinical pearl - 'radiological appearance, if the patient comes with an X-ray, of abscess in the lung which is not producing much sputum can have a cancer as its cause', a clinician should suspect it, and check if the history and examination support it.

\section{Conclusion}

In our ward rounds, clinical practice we hear and see, sometimes, symptoms and signs which have not been mentioned in standard recognized textbooks. We see deviations from classical picture of a disease. Most of us do not feel confident enough to write down for the scrutiny and opinion of the other clinicians based on their own experience. This brief article is a humble attempt reflecting the opinion on a few of my clinical experiences.

\section{References}

1. Douglas G, Nicol F, Robertson C. editors. Macleod's Clinical Examination. 13th edition. London. Elsevier. 2013; Ref.: https://bit.ly/318y1Dh

2. Glynn M. Doctor and Patient: General principles of history taking. In Glynn M, Drake WM. Editors. Hutchison's Clinical Methods: An integrated approach to clinical Practice. 23rd edition. London. Elsevier. 2012; 3. Ref.: https://bit.ly/2EQobMD

3. Salah. Ref.: https://bit.ly/2FqmCa3

4. Glossary of Islam. Ref.: https://bit.ly/2ljMoM3

5. Davenport R, Manji H. The Nervous System. In Douglas G, Nicol F, Robertson C. editors. Macleod's Clinical Examination. 13th edition. London. Elsevier. 2013; 263. Ref.: https://bit.ly/318y1Dh

6. Wagner LA. Imaging in Subdural Haematoma. Ref.: https://bit.ly/2Z7E6hs

7. Bell DJ, Gallard F. Large Unilateral Pleural Effusion. Ref.: https://bit.ly/2WhfSnM 